\title{
Resumo deTese
}

Contribuição da ultra-sonografia intra-operatória (USIO) no estudo do fígado em pacientes candidatos à ressecção hepática por metástase de adenocarcinoma colorretal.

Autor: Márcio Martins Machado.

Orientador: Giovanni Guido Cerri.

Tese de Doutorado. FMUSP, 2002.

Neste estudo discute-se a utilização da ultra-sonografia intra-operatória para a avaliação do fígado em pacientes candidatos a ressecção hepática por metástase de adenocarcinoma colorretal. São comparados, também, os resultados da ultra-sonografia intra-operatória, da ultra-sonografia/tomografia computadorizada helicoidal realizadas no pré-operatório, e os resultados da inspeção/palpação do fígado efetuadas durante a cirurgia.

Aultra-sonografia intra-operatória foi realizada com transdutor linear de freqüência central de 7,5 MHz. Foram analisados 15 pacientes, nos quais foram identificados 40 nódulos. Todos os nódulos foram confirmados como sendo metástases hepáticas de adenocarcinoma colorretal, por meio de exame histopatológico.
O planejamento cirúrgico inicial, baseado nas análises dos exames pré-operatórios de ultra-sonografia/tomografia computadorizada helicoidal, foi modificado em cinco pacientes $(33,3 \%)$, devido aos achados adicionais fornecidos exclusivamente pela ultra-sonografia intra-operatória.

Dos 40 nódulos, a ultra-sonografia intraoperatória identificou 38 (95\%); a inspeção/ palpação durante o ato cirúrgico, 31 (77,5\%); a ultra-sonografia/tomografia computadorizada helicoidal pré-operatórias, 26 (65,0\%). Portanto, a ultra-sonografia intra-operatória identificou $30,0 \%$ a mais de nódulos que os exames pré-operatórios de ultra-sonografia/tomografia computadorizada helicoidal, e esta diferença foi estatisticamente significante

A ultra-sonografia intra-operatória desempenha papel importante durante a cirurgia hepática devida a metástase de adenocarcinoma colorretal, mudando a conduta cirúrgica inicial em um número significativo de pacientes.

\section{Conclusões}

1. A ultra-sonografia intra-operatória mostrou-se com maior acuidade na identificação de metástases hepáticas quando comparada a ultra-sonografia/tomografia computadorizada helicoidal pré-operatórias.

2. A ultra-sonografia intra-operatória demonstra ser tambémsuperior ao estadiamento cirúrgico do fígado não-cirrótico, pela inspeção e palpação, além de contribuir no esclarecimento sobre a natureza dos nódulos intraparenquimatosos palpados pelo cirurgião.

3. A ultra-sonografia intra-operatória é importante na sua capacidade em determinar as relações vasculares dos tumores hepáticos, sendo o único método disponível de maneira dinâmica na sala de cirurgia, podendo ser interpretada dinamicamente por cirurgiões e radiologistas.

4. A ultra-sonografia intra-operatória demonstra ser capaz de mudar a conduta cirúrgica nos pacientes com adenocarcinoma colorretal metastático para o fígado, e que vão ser submetidos a laparotomia visando à ressecção hepática.

5. Existem situações em que a ultra-sonografia intra-operatória pode não identificar pequenos nódulos hepáticos, especialmente aqueles menores ou iguais a $5 \mathrm{~mm}$. 